\title{
Analysis on the Potential Clinical Bio-marks for Decabromodiphenyl Ether Exposure
}

\author{
Hongmei Wang ${ }^{1}$, Beidou $\mathrm{Xi}^{1}$, Hongyan Wang ${ }^{1,2}$, Han Zhang ${ }^{1 *}$, Congli $\mathrm{Ma}^{1,3}$, Yuguo Jiao ${ }^{3}$ and Yuejiao Zhang ${ }^{4,5}$ \\ ${ }^{1}$ State Key Laboratory of Environmental Criteria and Risk Assessment, Chinese Research Academy of Environmental Sciences, Chaoyang District, Beijing, China \\ ${ }^{2}$ The College of Environmental Science and Engineering, Nankai University, Nankai District, Tianjing, China \\ ${ }^{3}$ College of Life and Environmental Science, Minzu University of China, Haidian District, Beijing, China \\ ${ }^{4}$ Beijing Emergency Medical Center, Xicheng District, Beijing, China \\ ${ }^{5}$ Peking University Health Science Center, Haidian District, Beijing, China
}

\begin{abstract}
Decabromodiphenyl ether (BDE 209) was one of the flame retardants in a variety of commercial and household products. The toxicity of BDE 209 was thought to be associated with neurotoxicity, changes in fetal development, and endocrine disruption etc. Although different toxicology effects of BDE 209 exposure had been reported, the information of BDE 209 on Jurkat cells was still insufficient, and the molecular bio-marks were still unknown. In this research, the gene expression profiling was analyzed. Changes of gene expression induced by BDE 209 could be classified into neurotoxicity, apoptosis and reproductive toxicity. Quantifying microRNA expression levels was verified by real-time PCR. The expression levels of Brain-Derived Neurotrophic Factor (BDNF), Regulating synaptic membrane exocytosis 3 (RIMS3) and dihydropyrimidinase-like 3 (DPYSL3), which were associated with the neurotoxicity and brain development, presented trends of down-regulated. Based on the abundance of gene expression analysis in tissues and cells and taking the possibility of biological samples obtained for the clinical diagnosis into consideration, BDNF, that had been confirmed as one of the key genes in the neurotoxicity, was recommended as one of the main clinical bio-marks in the epidemiology, since it had been found abundant in the blood monocyte.
\end{abstract}

Keywords: Decabromodiphenyl Ether (BDE 209); Clinical biomarks; Brain-Derived Neurotrophic Factor (BDNF)

\section{Introduction}

Brominated Flame Retardants (BFRs) were chemicals widely used in electronic equipment, textiles and plastics for the prevention of fire. Over recent decades, concerns had been raised regarding some heavily used BFRs, since the levels in the environment had been found increasing. Among them, Decabromodiphenyl Ether (BDE 209) was one of the main BFRS for its large market amount. Due to their widespread use, persistence and bio-accumulative properties, BDE 209 had been detected in humans at high levels [1,2]. There were many ways that humans exposed to BDE 209, including ingestion of contaminated foods and incidental intake of Poly Brominated Biphenyl Ether (PBDE) contaminated dust [3-6]. Because of wide use in electronic products, BDE 209 had been reported to be released from the electronic waste (e-waste) recycles largely, and high levels were also found in people. BDE 209 as one of the predominant congeners was detected in indoor and outdoor dust samples that collected from an e-waste area, and the average exposure estimates of PBDEs via dusts were $470 \mathrm{ng} / \mathrm{d}, 329 \mathrm{ng} / \mathrm{d}$ and $188 \mathrm{ng} / \mathrm{d}$ for infants, toddlers and adults, respectively. These results indicated that dust might be a very important media of exposure for PBDEs in local residents [7].

Exposed to BDE 209 could cause adverse effects on human health. The relationships between BDE 209 and many adverse health effects had been found, it could be classified as neurodevelopment effects, reproductive effects, cancer, immunological and thyroid problems. No in vivo studies that specifically evaluated the immunosuppressive effects of decaBDE have been identified. However, in chronic dietary studies, decaBDE had been found to induce histological changes in lymphoid organs, including the spleen (fibrosis) and mandibular lymph nodes (hyperplasia) in male rats at a dose of $2.240 \mathrm{mg} / \mathrm{kg}$ day [8]. Although these histopathological changes might play an important role in flagging decaBDE for immunotoxicity, they were at the high end of the spectrum of doses evaluated, and lack of studies to investigate the functional effects on immune cells by decaBDE exposure - precluded complete assessment of its immunotoxic potential [8].

Neurotoxicity was thought as one of the main toxicities caused by BDE209. A recent study in adult mice found BDE 209 could act as a toxicant to neurodevelopment. In their study, exposure to decaBDE was linked with hyperactivity and reduced or lack of habituation, also worsening with age. Neurobehavioral derangements in adult mice exposed to BDE 209 during a defined period of neonatal brain development were reported, and it was taken as the toxicology terminal effects for deriving the criteria value, and a total uncertainty factor of 300 was considered to be adopted, based on the similar pharmacokinetic characteristics of BDE 209 across species. On June 30,2008 , the US EPA's IRIS updated their toxicological review on the BDE 209 and published a revised oral Reference Dose (RfD) of 0.007 $\mathrm{mg} / \mathrm{kg}$ day based on a No Observed Adverse Effect Level (NOAEL) for neurobehavioral effects of $2.22 \mathrm{mg} / \mathrm{kg}$-day [9]. Other experiments also reported that neonatal exposure to BDE 209 could cause dose-response changes in spontaneous behavior and cholinergic susceptibility in adult

*Corresponding author: Jinliang Zhang, State Key Laboratory of Environmental Criteria and Risk Assessment, Chinese Research Academy of Environmental Sciences, Anwaibeiyuandayangfang No.8, Chaoyangdistrict, 100012, PRC China Tel: 86(0)1084915212; Fax: 86(0)1084934276; E-mail: zjlbj2012@163.com

Received October 20, 2012; Accepted November 15, 2012; Published November 17,2012

Citation: Wang HM, Xi BD, Wang HY, Zhang JL, Ma CL, et al. (2012) Analysis on the Potential Clinical Bio-marks for Decabromodiphenyl Ether Exposure. J Mol Biomark Diagn 3:137. doi:10.4172/2155-9929.1000137

Copyright: $\odot 2012$ Wang HM, et al. This is an open-access article distributed under the terms of the Creative Commons Attribution License, which permits unrestricted use, distribution, and reproduction in any medium, provided the original author and source are credited 
Citation: Wang HM, Xi BD, Wang HY, Zhang JL, Ma CL, et al. (2012) Analysis on the Potential Clinical Bio-marks for Decabromodiphenyl Ether Exposure. J Mol Biomark Diagn 3:137. doi:10.4172/2155-9929.1000137

Page 2 of 6

mice [10-12]. Different effects were reported by various experiments, demonstrating that mice treated with $20 \mathrm{mg} / \mathrm{kg}$-day BDE 209 initially had higher activity and an increased habituation [13], while Viberg group reported mice and rats treated with or $\geq 20 \mathrm{mg} / \mathrm{kg}$ BDE 209 or mice treated with $2 \mathrm{mg} / \mathrm{kg}$ BDE209 had lower initial activity and decreased habituation, although appropriate statistical methods might have affected results $[10,11]$. Although there were some debates on the RfD for BDE209, its adverse effects on neurotoxicity had been confirmed [14]. The current state of knowledge on the molecular toxicology effects of BDE 209 was limited, especially in human studies. It was still lack of clinical bio-marks for the epidemiology study. Here, cell line technique was taken to select sensitively changed genes by microarray experiment, and potential clinical bio-marks for decabromodiphenyl ether exposure were probed.

\section{Materials and Methods}

\section{Chemicals and reagents}

BDE 209 was obtained from Sigma. All other chemicals were purchased from sinapharm chemical reagent Beijing Co., ltd unless otherwise stated. Tissue culture media and reagents were broughtfrom Hyclone (SH30809.018 nwm 0531, Beijing).

\section{Cell culture and chemical exposure}

The Jurkat cell line was obtained from Peking union cell culture center and cultured in Hyclone modified RPMI-1640 medium supplemented with $10 \%$ GIBCO serum as nutrient mixture at $37^{\circ} \mathrm{C}$ in a $5 \% \mathrm{CO}_{2}$ atmosphere. Cells were exposed to chemicals dissolved in $0.1 \%$ Dimethyl Sulfoxide (DMSO) (final concentration) for $48 \mathrm{~h}$. Cells in the control group were incubated with DMSO only. The concentrations of treated groups were set as follows: $0.5,10,20$ and $40 \mu \mathrm{M}$. The cells were maintained in culture for 7 days before treatment in a humid chamber at $37^{\circ} \mathrm{C}$ in $95 \% \mathrm{O}_{2} / 5 \% \mathrm{CO}_{2}$. This initial culture period allowed for a moderate increase in cell numbers. Cell counts were determined over the cultural period using a hemocytometer.

\section{Microarray analysis}

Total RNA was extracted using the E.Z.N.A: Total RNA Kit I (Omega, USA) and about $300 \mathrm{ng}$ were reversely transcribed. The resulting cRNA was synthesized by in vitro transcription and purified using Kit1-Eukaryotic RNA General Amplification Kit (CapitalBio, China). The above quantitative cRNA was reversely transcribed, purified and labeled with Cy3/5-dCTP using LuxScanTM ${ }^{\circ}$ General Biochip Labeling Kit (Cy3/5) (CapitalBio, China). Fragmented, fluorescently-labeled cDNAs $(2 \mu \mathrm{g})$ were hybridized to GeneChip arrays using instrument according to its protocol. The arrays were then washed according to Guo et al. [15]. Microarrays were scanned with a LuxScan 10K-A laser confocal scanner, and the images obtained were then analyzed using LuxScan 3.0 software (CapitalBio, China). DNAChip analyser (dChip) software was used to normalize the fluorescence intensity over multiple arrays, to calculate model-based expression values from the differences between perfect match and mismatch probes in the cell intensity files [15]. In addition, the software was employed to determine the probability of having a particular number of genes of a certain gene ontology (GO) biological process in the generated list of filtered genes, using hypergeometric distribution; GO enrichment was assumed at $\mathrm{P}<0.001$. For all samples, signals were preprocessed with the software developed by Capitalbio to attain altered expression of genes. Adjust data with relative tools and normalize signals with the software Cluster 3.0 before average linkage clustering. The hierarchical clustering diagram of BDE 209 induced expression changes were done by launching java tree view and adjusting several parameters.

\section{Real-time quantitative PCR}

Real-Time quantitative PCR (RT-PCR) was performed. The reaction mix consisted of Brilliant SYBR Green Q-PCR Master Mix (Strata gene), $2.5 \mathrm{mM} \mathrm{MgCl}, 150 \mathrm{nM}$ each primer and $1 \mu \mathrm{l}$ of cDNA. Primer sequences were shown in table 1 . The amplification protocol consisted of a denaturation step at $94^{\circ} \mathrm{C}$ for 5 min and 40 cycles of $95^{\circ} \mathrm{C}$ for $30 \mathrm{~s}, 57^{\circ} \mathrm{C}$ for $1 \mathrm{~min}$ and $72^{\circ} \mathrm{C}$ for $1 \mathrm{~min}$. The instrument for RT-PCR is Bio-rad, IQ5 Multicolor Real-Time PCR Detection System (575BR, USA).

\begin{tabular}{|c|c|c|c|c|c|c|}
\hline \multirow{2}{*}{ Probe set ID } & \multirow{2}{*}{ Gene ID } & \multirow{2}{*}{ Gene title } & \multicolumn{3}{|c|}{ *average of fold changes $\left(2^{-\Delta \Delta c t}\right)$} & \multirow{2}{*}{$\begin{array}{l}\text { Trend of the changes } \\
\text { to the control }\end{array}$} \\
\hline & & & $5 \mu \mathrm{mol} / \mathrm{l}$ & $20 \mu \mathrm{mol} / \mathrm{l}$ & $40 \mu \mathrm{mol} / \mathrm{l}$ & \\
\hline \multicolumn{7}{|l|}{ neurotoxicity } \\
\hline Pr125404.1 & 627 & Brain-Derived Neurotrophic Factor (BDNF) & 0.68 & 0.48 & 0.24 & $\downarrow$ \\
\hline Pr132072.1 & 1809 & Dihydropyrimidinase-Like 3 (DPYSL3) & 0.74 & 0.18 & 0.002 & $\downarrow$ \\
\hline Pr172403.1 & 2556 & Gamma-Aminobutyric Acid (GABA) A Receptor, Alpha 3 (GABRA3) & 8.40 & 0.53 & 0.93 & \\
\hline Pr001192959.1 & 342035 & Gliomedin (GLDN) & 0.14 & 0.24 & 0.31 & \\
\hline Pr149117.1 & 2861 & G Protein-Coupled Receptor 37 (GPR37) & 5.88 & 1.63 & 7.41 & $\uparrow$ \\
\hline Pr169768.1 & 9783 & Regulating Synaptic Membrane Exocytosis 3 (RIMS3) & 1.13 & 6.20 & 4.54 & $\uparrow$ \\
\hline Pr129608.1 & 3354 & 5-Hydroxytryptamine Receptor 1E(HTR1E) & 0.42 & 0.22 & 0.28 & \\
\hline Pr153563.1 & 246213 & Solute Carrier Family 17 Member 8 (SLC17A8) & 0.84 & 0.26 & 0.16 & $\downarrow$ \\
\hline \multicolumn{7}{|l|}{ transcription } \\
\hline Pr006603767.1 & 256297 & Pancreas Transcription Factor 1 Subunit Alpha (PTF1A) & 2.77 & 2.8 & 2.14 & $\uparrow$ \\
\hline Pr000110.1 & 54892 & Non-SMC Condensin II Complex, Subunit G2 (NCAPG2) & 2.76 & 0.21 & 0.49 & \\
\hline Pr138264.1 & 7832 & B-Cell Translocation Gene 2 (BTG2) & 0.87 & 0.65 & 0.46 & $\downarrow$ \\
\hline Pr135451.1 & 5585 & Protein Kinase N1 (Pkn1) & 2.56 & 0.11 & 0.54 & \\
\hline Pr161502.1 & 5162 & Pyruvate Dehydrogenase (Lipoamide) Beta (Pdhb) & 0.66 & 0.14 & 0.06 & $\downarrow$ \\
\hline \multicolumn{7}{|l|}{ apoptosis } \\
\hline Pr181057.1 & 27063 & Ankyrin Repeat Domain-containing protein 1 (ANKRD1) & 0.2 & 0.14 & 0.13 & $\downarrow$ \\
\hline \multicolumn{7}{|c|}{ reproductive toxicity } \\
\hline Pr143524.1 & 353189 & Solute Carrier Organic anion transporter family, member 4C1 (SLCO4C1) & 0.34 & 0.20 & 0.11 & $\downarrow$ \\
\hline Pr001042985.1 & 27285 & Testicular Tektin B1-Like Protein (TEKT2) & 0.27 & 0.14 & 0.11 & $\downarrow$ \\
\hline
\end{tabular}

Table 1: Validation of gene expression changes by Real-time RT-PCR. 


\section{Results}

\section{Gene expression profiling}

To investigate the toxicological action of the BDE 209, we incubated Jurkat cells with 5, 20 and $40 \mu \mathrm{M}$ BDE 209 for $48 \mathrm{~h}$, and examined changes in global mRNA profiles using Capitalbio high-density oligonucleotide arrays. Experiments were performed on three separate occasions and, in each experiment, cells in the control group were incubated with vehicle (DMSO) under the same process. Capitalbio high-density oligonucleotide arrays contained probes with 35,000 transcripts and variants. A total of 403 annotated and unknown genes or expressed sequence tags, which expression altered obviously after exposure to BDE 209, were filtered by Cluster 3.0. It was apparent from the two-way hierarchical clustering analysis of the filtered genes that the effects of BDE 209 on Jurkat cells varied from genes, no consistency between concentrations of BDE 209 and the extent of gene up-regulated or down-regulated were found (Figure 1). Mechanisms of significantly altered genes induced by BDE 209 could be mainly classified into three categories: neurotoxicity, apoptosis and reproductive toxicity.

\section{Validation of gene expression changes by Quantitative PCR}

Both factors were considered for the key genes selected to validate changes of gene expression, including great differences in gene expression and protein encoded by these genes reported previously. These selected genes were further validated by real-time quantitative PCR (Table 1). The levels of BDNF were found down-regulated significantly (Table 1). Although there was no dose-response curve found, the trend that BDNF decreased with the increase of exposed concentration of BDE 209 had been confirmed. The protein encoded by this gene was a member of the nerve growth factor family. It could be induced by cortical neurons, and it was necessary for survival of striatal neurons in the brain. BDNF might also play a role in the regulation of stress response and in the biology of mood disorders. Moreover, it had been described as multiple transcript variants encoding distinct isoforms. This gene was associated with both Alzheimer's and Huntington disease. In our study, the decrease of BDNF indicated that BDE 209 might play a toxic effect though affecting the BDNF levels. Some previous studies on animals had reported that the BDNF expression level decreased in hippocampa of male SD rats exposed to BDE 209, and there was a significant negative trend of BDNF gene expression over BDE 209 doses. The result further revealed that BDE 209 could induce disability of male rats in their learning and memory [16]. Another study also supported this view that neonatal BDE 209 exposure could affect levels of BDNF [17].

Another important gene related with neurotoxicity, dihydropyrimidinase-like 3 (DPYSL3), was found with similar decreased trend as BDNF (Table 1), and the findings showed much more differences of DPYSL3 between treated groups and the control group in our study. DPYSL3 was regarded as necessary for signaling by class 3 semaphorins and subsequent remodeling of the cytoskeleton. It played an important role in axon guidance, neuronal growth cone collapse and cell migration. Such proteins encoded by Dpysl2 (CRMP2) and Dpysl3 (CRMP4) genes, had been involved in neuronal polarity and axon elongation in cultured neurons. They were expressed in various regions of the developing nervous system. In dpysl2 and dpysl3 double morphants, Rohon-Beard (RB) primary sensory neurons that were originally located bilaterally along the midline shifted their position to a more medial location in the dorsal-most part of spinal cord. A similar phenotype was observed in the cdk 5 and dyrk2 double morphants [18]. The level of DPYSL3 expression was seldom reported in the previous study.
Other genes related with neural system signal transfer pathway had also been found to be affected by the BDE 209. 5-Hydroxytryptamine Receptor 1E (HTR1E) and solute carrier family 17 member 8 (SLC17A8) had been found to be down-regulated (Table 1). Proteins encoded by these genes were important to mediate the uptake of the neurotransmitter of the synapsis. Animal experiment had proved neurotoxic effect of synaptophysin and tau of neonatal ontogeny caused by BDE 209, and it showed that long period of BDE 209 exposure could affect the development of nerve cell, change the ultra structure of synapsis and lower the density of synapsis [19]. In the current research, it was not only confirmed that BDE 209 affected the levels of genes synaptophysin in the developing brain but also pointed out it could

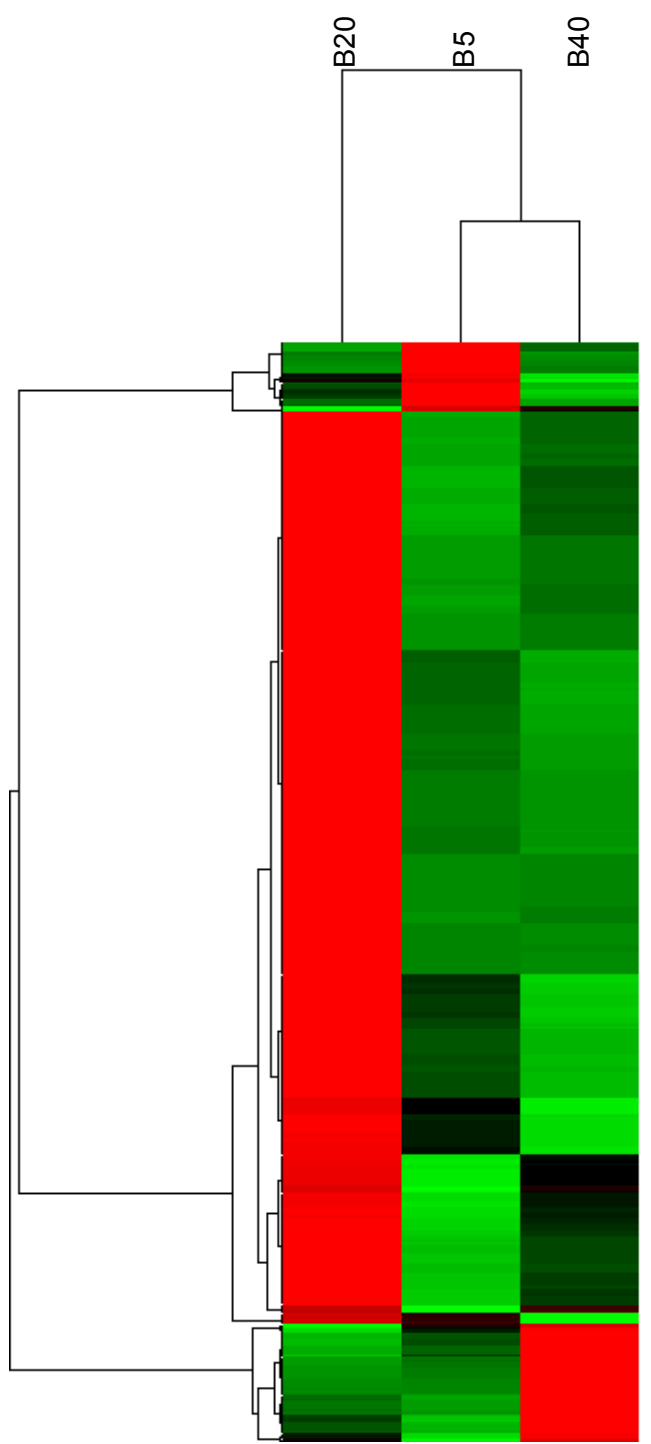

Figure 1: Gene expression profiling. Hierarchical clustering diagram of BDE 209 induced expression changes. Jurkat cells were incubated with 5 20 and $40 \mu \mathrm{M}$ BDE 209 with DMSO (as control) for $48 \mathrm{~h}$, all in triplicate. In the heatmap, rows represent individual genes and columns display the gene expression levels in each independent sample. Red color represents an expression level above the mean value of expression of a gene across all samples, black represents the mean and green color represents an expression level below the mean. 
decrease the uptake of the neurotransmitter of the synapsis by reducing the levels of genes SLC17A8 and HTR1E.

Regulating synaptic membrane exocytosis 3 (RIMS3), which encoded a protein acted as regulated synaptic membrane exocytosis (By similarity) was found to be increased when exposed to BDE 209 in our study (Table 1). A study also found this protein in synaptophysin had increased significantly in the hippocampus, but not in the cerebral cortex, in mice, 7 days after being exposed to BDE 209 [17,20]. Expressions of other genes related with the transcriptional and cell cycle were also found varied. Pancreas transcription factor 1 subunit alpha (PTF1A) and non-SMC condense in II complex, subunit G2 (NCAPG2) showed increased trend in treated groups than that of the control group (Table 1). PTF1A was a transcriptional activator. It could bind to the E-box consensus sequence 5'-CANNTG-3', and play an important role in determining whether cells allocated to the pancreatic buds continue towards pancreatic organogenesis or revert back to duodenal fates. It was also important in cerebellar development [21]. Genes related with cell cycle were also found decreased. NCAPG2, which was considered as regulatory subunit of the condensin- 2 complex, established mitotic chromosome architecture and was involved in physical rigidity of the chromatid axis. It showed a reverse trend compared with the BDE209 concentration (Table 1). The same result was found in the level of B-cell translocation gene 2 (BTG2). This gene was involved in the growth and differentiation of the neuronal precursors and in mitochondrial depolarization and neurite outgrowth. Roles of the path of the two genes were still unknown.

Protein Kinase N1 (PKN1), involved in various processes such as regulation of the intermediate filaments of the actin cytoskeleton, cell migration, tumor cell invasion and transcription regulation, was decreased too. It acted as a key co-activator of Androgen Receptor (ANDR)-dependent transcription. There were still not enough reports on the relationship between PKN1 and BDE 209 exposure. Pyruvate Dehydrogenase (Lipoamide) Beta (PDHB), which was PKC-related serine/threonine-protein kinase regulating the cytoskeletal network by phosphorylating proteins, also decreased obviously (Table 1). It was associated with synthesis of many important enzymes, mediating phosphorylation of 'Thr-11' of histone H3 (H3T11ph), acting as a specific tag for epigenetic transcriptional activation that promotes demethylation of histone H3 'Lys-9' (H3K9me) by KDM4C/JMJD2C. The expression changes of this gene might be harmful to the normal enzyme synthesis. In our study, there was no linear dose-response relationship in above genes, but the findings indicated that BDE 209 might play its toxicological roles by affecting transcription and altering cell cycles. The toxic mechanisms of BDE 209 could be more complex than the previously reported ones. Apoptosis of human hepatoma cells Hep G2 byBDE-209 was reported by the previous study. Repeated dietary studies showed that adverse liver effects were more severe in rats and mice when administered lower doses of PBDEs [22]. In present study, Ankyrin Repeat domain-containing protein 1 (ANKRD1), which related with induction of apoptotic cell death in hepatoma cells, showed the decrease trend.

PBDEs had been proved to be able to impair sperm development permanently in rodent studies [23]. Previous researches had reported that exogenous BDE 209 could cause mouse sperm DNA damage and lead to DNA chain breakage, which showed obvious dose dependence [24]. We analyzed testicular Tektin B1-like protein (TEKT2), the expression of which was down-regulated in the microarray experiment, and the results were validated by RT-PCR. PBDE affected the sperm quality had been confirmed before [25], but the mechanism was rarely reported. TEKT2, being one of structural component of ciliary and flagella microtubules, played a key role in the assembly or attachment of the inner dynein arm to microtubules in sperm flagella and tracheal cilia. It formed filamentous polymers in the walls of ciliary and flagella microtubules. It could also affect greatly the reproductive process. Our findings revealed that BDE 209 exposure caused the level of TEKT2 decrease, which might be one of the explanations for BDE 209 reproductive toxicity.

The results here suggested that the expression of some important genes associated with the neurotoxicity could be affected by BDE 209 . Though the molecular mechanisms were not probed in our study, the findings showed the key genes affected by it. It might be a useful way to find the potential molecular bio-marks for further research by cell line technique. These genes might play important roles in explaining the neurotoxic mechanism. Furthermore, it suggested that certain proteins encoded by these genes involved in developmental processes might serve as markers of developmental neurotoxicity.

\section{Abundance of gene expression in tissues and cells}

The expression abundances of different genes were summarized in table 2. Data was obtained from http://www.genecards.org/.

\section{Discussion}

Studies characterising potential effects in humans were relatively limited. As public health interest is increasing, additional epidemiological investigations were conducted and thus the results published. These studies generally focused on three main outcomes: endocrine disruption, neurotoxicity, and reproductive toxicity, etc. $[26,27]$. It still lacks mechanistic supports to the overall findings. The available epidemiological studies tended to be based on key toxicological findings in laboratory studies as well as knowledge about compounds with similar structure, such as the Polychlorinated Biphenyls (PCBs).

None of the available clinical bio-marks were reported to evaluate BDE 209 in clinical diagnosis. There were two important aspects on the study of potential clinical bio-marks for decabromodiphenyl ether exposure, firstly; it could provide the index to monitor the health effect of occupational peoples and non-occupational people. The second, it could help to evaluate human health risk by interpreting the toxicological effects. For the potential clinical bio-marks selected, the high-throughput screening technique was the optimized method. In this study, some key genes had been selected and verified by RT-PCR (Tables 1 and 2). But not all of these genes could act as potential clinical bio-marks for BED209. The key points were that the abundance of gene expression in tissues and cells should not be neglected. In addition, the possibility of obtaining the biological samples should be taken into consideration. Traditional samples, for example, blood, should be preferred to obtain. According to online information, potential clinical bio-marks were summarized in table 3. By analysis of the genes of BDNF, SLC17A8, NCAPG2, PKN1 and PDHB, we recommended protein encoded by BDNF acted as one of the main clinical bio-marks. Though the expression abundances of gene PKN1 and PDHB were reported large enough in tissue/fluid, they were not suitable to be biomarks because both of them were associated with synthesis of many important enzymes, mediating phosphorylation of 'Thr-11' of histone H3 (H3T11ph). Their changes of expression level might be affected through other important enzymes synthesis, such as oxidationreduction reaction and phosphorylation. Conversely, BDNF, which had been confirmed as one of the key genes in the animal neurotoxicity, was found abundant in the blood monocyte, and it could act as a main clinical bio-mark in the epidemiology. 
Citation: Wang HM, Xi BD, Wang HY, Zhang JL, Ma CL, et al. (2012) Analysis on the Potential Clinical Bio-marks for Decabromodiphenyl Ether Exposure. J Mol Biomark Diagn 3:137. doi:10.4172/2155-9929.1000137

Page 5 of 6

\begin{tabular}{|c|c|c|c|c|c|c|c|c|c|c|c|c|c|c|}
\hline & $\begin{array}{l}\text { Blood } \\
\text { plasma }\end{array}$ & $\begin{array}{l}\text { Blood } \\
\text { erythroleukemia }\end{array}$ & $\begin{array}{l}\text { Blood } \\
\text { monocyte }\end{array}$ & $\begin{array}{l}\text { Blood } \\
\text { neutrophil }\end{array}$ & $\begin{array}{l}\text { Blood } \\
\text { B-lymphocyte }\end{array}$ & $\begin{array}{l}\text { Blood } \\
\text { T-lymphocyte }\end{array}$ & $\begin{array}{l}\text { Blood } \\
\text { T-Lymph } \\
\text { JURKAT }\end{array}$ & $\begin{array}{l}\text { Kidney } \\
\text { HEY- } \\
293\end{array}$ & $\begin{array}{l}\text { Kidney } \\
\text { Urine }\end{array}$ & $\begin{array}{l}\text { Lung } \\
\text { Alveolar } \\
\text { lavage }\end{array}$ & liver & $\begin{array}{l}\text { Liver } \\
\text { HuH-7 } \\
\text { cancer }\end{array}$ & $\begin{array}{l}\text { Pancreas } \\
\text { cancer }\end{array}$ & $\begin{array}{l}\text { Prostate } \\
\text { cancer }\end{array}$ \\
\hline BDNF & & & * & & & & & & & & & & & \\
\hline DPYSL3 & & & & & & & & *** & & & + & & & \\
\hline \multicolumn{15}{|l|}{ GABRA3 } \\
\hline GLDN & & & & & & & & * & & & & & & \\
\hline GPR37 & & & & & & & & * & & & & & & \\
\hline \multicolumn{15}{|l|}{ RIMS3 } \\
\hline \multicolumn{15}{|l|}{ HTR1E } \\
\hline SLC17A8 & & & & & + & & & & & & & & & \\
\hline PTF1A & & & & & & & & * & & & & & & \\
\hline NCAPG2 & & + & & & & & & ** & & & & & & \\
\hline BTG2 & & & & & & & & * & & & & & & \\
\hline PKN1 & & ++ & + & & + & + & & ** & & & & & * & \\
\hline PDHB & & ++ & ++ & + & ++ & +++ & & $* * *$ & + & & ++ & ** & & ** \\
\hline ANKRD1 & & & & & & & & * & & & & & & \\
\hline TEKT2 & & & & & & & & * & & & & & & \\
\hline
\end{tabular}

Normalized count: *:0-1; **:1-10; ***:10-100; +:0-1; ++:1-10; +++:10-100

*: abundance of genes expression in cell; + : abundance of genes expression in tissue

Table 2: Abundance of genes expression in tissues and cells.

\begin{tabular}{|c|c|c|c|c|c|c|c|}
\hline & Blood plasma & Blood erythroleukemia & Blood monocyte & Blood neutrophil & Blood B-lymphocyte & Blood T-lymphocyte & Blood T-Lymph JURKAT \\
\hline BDNF & & & * & & & & \\
\hline SLC17A8 & & & & & + & & \\
\hline NCAPG2 & & + & & & & & \\
\hline PKN1 & & ++ & + & & + & + & \\
\hline PDHB & & ++ & ++ & + & ++ & +++ & \\
\hline
\end{tabular}

Normalized count: *:0-1; **:1-10; ***:10-100; +:0-1; ++:1-10; +++:10-100

*: abundance of genes expression in cell; + : abundance of genes expression in tissue

Table 3: Potential Clinical biomarks for decabromodiphenyl ether exposure.

In this paper, we also suggest to carry out more studies on the molecular bio-marks for better understanding of the potential adverse effects of BDE 209 exposure. In addition, more researches on mechanistic processes should be performed to understand the mechanisms.

\section{Acknowledgements}

The research presented here was supported by MEP-PRC Project 2010kyyw07 \& HBGY 200909079, the authors are extremely grateful to staffs at the Department of Environment and Health for their health statistics technical assistance. The findings and conclusions in this report are those of the authors. The authors declare they have no competing financial interests.

\section{References}

1. Thomas GO, Wilkinson M, Hodson S, Jones KC (2006) Organohalogen chemicals in human blood from the United Kingdom. Environ Pollut 141: 30-41.

2. Sun S, Zhao J, Leng J, Wang P, Wang Y, et al. (2010) Levels of dioxins and polybrominated diphenyl ethers in human milk from three regions of northern China and potential dietary risk factors. Chemosphere 80: 1151-1159.

3. Jiang Y, Wang X, Zhu K, Wu M, Sheng G, et al. (2012) Occurrence, compositional patterns, and possible sources of polybrominated diphenyl ethers in agricultural soil of Shanghai, China. Chemosphere 89: 936-943.

4. Wei H, Aziz-Schwanbeck AC, Zou Y, Corcoran MB, Poghosyan A, et al (2012) Polybromodiphenyl ethers and decabromodiphenyl ethane in aquatic sediments from southern and eastern Arkansas, United States. Environ Sci Technol 46: 8017-8024

5. Zhang Y, Luo XJ, Wu JP, Liu J, Wang J, et al. (2010) Contaminant pattern and bioaccumulation of legacy and emerging organhalogen pollutants in the aquatic biota from an e-waste recycling region in South China. Environ Toxicol Chem 29: $852-859$

6. Zhang W, Zhang M, An S, Xiong B, Li H, et al. (2012) Ecotoxicological effects of decabromodiphenyl ether and cadmium contamination on soil microbes and enzymes. Ecotoxicol Environ Saf 82: 71-79.

7. Wang J, Chen SJ, Tian M, Ma YJ, Luo XJ, et al. (2010) Polybrominated diphenyl ethers (PBDEs) in indoor and outdoor dust from an electronic waste (e-waste) recycling area in South China: contamination and human exposure. Huan Jing Ke Xue 31: 173-178.

8. National Toxicology Program (1986) Toxicology and carcinogenesis studies of decabromodiphenyl oxide (CAS No. 1163-19-5) in F344/N rats and B6C3F1 mice (feed studies).

9. IRIS (2008) Toxicological Review of Decabromodiphenyl Ether (BDE-209) (CAS No. 1163-19-5) in Support of Summary Information on the Integrated Risk Information System (IRIS). EPA/635/R-07/008F.

10. Viberg H, Fredriksson A, Eriksson $\mathrm{P}$ (2003) Neonatal exposure to polybrominated diphenyl ether (PBDE 153) disrupts spontaneous behaviour, impairs learning and memory, and decreases hippocampal cholinergic receptors in adult mice. Toxicol Appl Pharmacol 192: 95-106.

11. Viberg H, Fredriksson A, Eriksson $P$ (2007) Changes in spontaneous behaviour and altered response to nicotine in the adult rat, after neonatal exposure to the brominated flame retardant, decabrominated diphenyl ether (PBDE 209). Neurotoxicology 28: 136-142.

12. Johansson N, Viberg H, Fredriksson A, Eriksson P (2008) Neonatal exposure to deca-brominated diphenyl ether (PBDE 209) causes dose-response changes in spontaneous behaviour and cholinergic susceptibility in adult mice. Neurotoxicology 29: 911-919.

13. Rice DC, Reeve EA, Herlihy A, Zoeller RT, Thompson WD, et al. (2007) Developmental delays and locomotor activity in the C57BL6/J mouse following neonatal exposure to the fully-brominated PBDE, decabromodiphenyl ether. Neurotoxicol Teratol 29: 511-520.

14. Goodman JE (2009) Neurodevelopmental effects of decabromodiphenyl ethe (BDE-209) and implications for the reference dose. Regul Toxicol Pharmaco 54: $91-104$. 
Citation: Wang HM, Xi BD, Wang HY, Zhang JL, Ma CL, et al. (2012) Analysis on the Potential Clinical Bio-marks for Decabromodiphenyl Ether Exposure. J Mol Biomark Diagn 3:137. doi:10.4172/2155-9929.1000137

Page 6 of 6

15. Guo Y, Chen Z, Zhang L, Zhou F, Shi S, et al. (2008) Distinctive microRNA profiles relating to patient survival in esophageal squamous cell carcinoma. Cancer Res 68: 26-33.

16. Pu R, Zhou GJ, Ma Li, Zhang DC (2011) Effects of Decabromodiphenyl Ethe Exposure on Learning And Memory Ability and Hippocampal BDNF Gene Expression of Male Rat. Chinese Journal of General Practice 3: 339-341.

17. Viberg $\mathrm{H}$ (2009) Neonatal ontogeny and neurotoxic effect of decabrominated diphenyl ether (PBDE 209) on levels of synaptophysin and tau. Int J Dev Neurosci 27: 423-429.

18. Tanaka H, Morimura R, Ohshima T (2012) Dpysl2 (CRMP2) and Dpysl3 (CRMP4) phosphorylation by Cdk5 and DYRK2 is required for proper positioning of Rohon-Beard neurons and neural crest cells during neurulation in zebrafish. Dev Biol 370: 223-236.

19. Lin Y, Zheng Y, Tao S, Chen SQ, Chen DJ (2009) Effect of moternal BDE 209 exposure on neural development and ultramicro structure of synapsis of off springs. Prog Obstet Gynecol. 18: 8-10.

20. Viberg $\mathrm{H}$, Mundy W, Eriksson $\mathrm{P}$ (2008) Neonatal exposure to decabrominated diphenyl ether (PBDE 209) results in changes in BDNF, CaMKII and GAP43 , biochemical substrates of neuronal survival, growth, and synaptogenesis. Neurotoxicology 29: 152-159.

21. Adell T, Gómez-Cuadrado A, Skoudy A, Pettengill OS, Longnecker DS, et al. (2000) Role of the basic helix-loop-helix transcription factor p48 in the differentiation phenotype of exocrine pancreas cancer cells. Cell Growth Differ 11: $137-147$
22. Agency for Toxic Substances and Disease Registry (2004) Toxicological Profile for Polybrominated Biphenyls and Polybrominated Diphenyl Ethers. US Department of Health and Human Services, Atlanta, US.

23. Wilford BH, Shoeib M, Harner T, Zhu J, Jones KC (2005) Polybrominated diphenyl ethers in indoor dust in Ottawa, Canada: implications for sources and exposure. Environ Sci Technol 39: 7027-7035

24. Wang ZX, Duan HY, Wang L, Chen DJ (2011) Mouse sperm DNA damage induced by exogenous BDE-209. Nan Fang Yi Ke Da Xue Xue Bao 31: 108112

25. Abdelouahab N, Ainmelk Y, Takser L (2011) Polybrominated diphenyl ethers and sperm quality. Reprod Toxicol 31: 546-550.

26. Julander A, Karlsson M, Hagström K, Ohlson CG, Engwall M, et al. (2005) Polybrominated diphenyl ethers--plasma levels and thyroid status of workers at an electronic recycling facility. Int Arch Occup Environ Health 78: 584-592.

27. Yuan J, Chen L, Chen D, Guo H, Bi X, et al. (2008) Elevated serum polybrominated diphenyl ethers and thyroid-stimulating hormone associated with lymphocytic micronuclei in Chinese workers from an E-waste dismantling site. Environ Sci Technol 42: 2195-2200.

28. Fenicia L, Anniballi F, De Medici D, Delibato E, Aureli P (2007) SYBR green real-time PCR method to detect Clostridium botulinum type A. Appl Environ Microbiol 73: 2891-2896. 